\section{Getting Practical About Recertification}

Years ago, when recertification became the rule, I breathed a sigh of relief when I heard that I would be grandfathered (grandmothered?) in and therefore exempted from being tested routinely on information I would not be regularly using in my practice. You see, by that time, I had already differentiated into gastrointestinal oncology and my practice was limited to that population. I still attended on our inpatient service, but inpatient oncology is programmed with planned admissions for protocol chemotherapy or complications of disease (or treatment of disease) that really require general medical or surgical attention rather than the sophisticated nuances of oncologic care.

Now, I admit, I am a bit of a coward. I've never been certain that I could keep up with an expanding knowledge base and actually pass these tests. And as I witness the explosion of new targeted drug approvals and new strategies of care, often based on sophisticated biomarkers, I am even less certain. Please don't get the idea that I don't want to stay current-I desperately do. I attend conferences and listen carefully and try to retain as much as possible. But when you don't use knowledge in day-to-day practice, it's very hard to make it stick.

In that same framework, I have come to admire my colleagues in community practice for their ability to deliver the highest possible care for patients with cancer. They don't have the luxury of focusing on just one disease or a group of diseases. They must be fluent in the details of therapy for a wide array of malignancies, especially the most common diseases, such as lung, breast, colon, and prostate cancers. They must also know when to ask, where to look, and who to call for help.

I recently reached out to a colleague in the community, Daniel Mirda, MD, to find out how it's done. How does the average oncologist keep up? I selected Dan for a couple of reasons. First, he's a top notch general oncologist in the nearby town of Napa and shares in the care of many patients who are also seen at my institution. In addition, Dan is the president of the Association of Northern California Oncologists (ANCO); in that capacity, he has regional and national influence on policy. His answers to my questions are detailed in his commentary, "Keeping Up in the Community," in this issue (page 754). Please take a few minutes to read it. He provides great insight into this complicated issue and provides some ideas about alternate ways to ensure competency.

I do think it's time to revisit recertification. The body of knowledge in cancer medicine has expanded to the point that it's impossible for any individual to know it all. We all recognize our limitations and try hard to maintain our competencies in selected areas. I agree that we should be vigilant about ensuring competency. That's essential to public health. You must prove that you are competent to care for patients. But let's get real and tailor competency testing to what we actually do.

What do you think? Please e-mail correspondence (include contact information) to JNCCN@nccn.org or log into www.editiorialmanager.com/JNCCN to submit a Letter to the Editor.

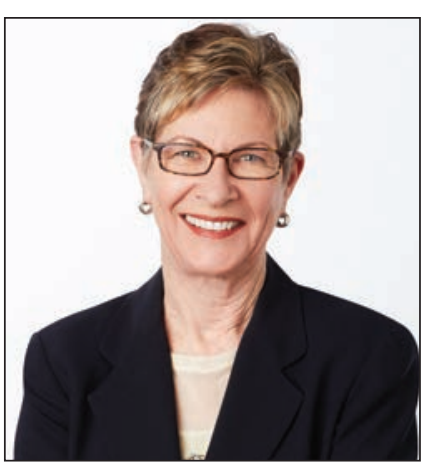

Margaret Tempero, MD

Margaret Tempero, MD, is a Professor of Medicine and Director of the UCSF Pancreas Center and editor-in-chief of JNCCN. Her research career has focused on pancreatic ductal adenocarcinoma, especially in the area of investigational therapeutics. Dr. Tempero has served on the ASCO Board of Directors and as ASCO President. She currently serves on the ASCO Conquer Cancer Foundation Board. She codirected the AACR/ASCO Methods in Clinical Cancer Research and taught this course and similar courses in Europe and Australia. She was founding Chair of the $\mathrm{NCl}$ Clinical Oncology Study Section and served as a member and Chair of the NCl Board of Scientific Counselors Subcommittee A. She is a member of the Scientific Steering Committee and Chair of the Clinical and Translational Study Section for the Cancer Prevention \& Research Institute of Texas. She is or has been on the Scientific Advisory Boards of the Lustgarten Foundation, the Pancreatic Cancer Action Network, the $V$ Foundation, The Alberta Canada Cancer Board, and the EORTC. She served as a member of the Oncology Drug Advisory Committee for the FDA. She has served as Deputy Director and Interim Director for the UNMC Eppley Cancer Center. She is Chief Emeritus of the Division of Medical Oncology at UCSF and served as the founding Deputy Director and Director of Research Programs at the UCSF Helen Diller Family Comprehensive Cancer Center.

doi:10.6004/jnccn.2017.0110

The ideas and viewpoints expressed in this editorial are those of the author and do not necessarily represent any policy, position, or program of NCCN. 